\title{
AS REFORMAS RELIGIOSAS E O NASCIMENTO DA ESCOLARIZAÇÃO OCIDENTAL
}

\author{
RELIGIOUS REFORMS AND BIRTH \\ OF WESTERN SCHOOLING \\ LAS REFORMAS RELIGIOSAS Y EL NACIMIENTO DE
LA ESCOLARIZACIÓN OCCIDENTAL
}

Norberto DallabridA ${ }^{\mathrm{I}}$

Resumo O presente artigo sustenta que as reformas religiosas construíram o nascimento da escolarização ocidental a partir de diferentes matrizes cristãs - protestantes e católica. Trata-se de um deslocamento histórico - no sentido foucaultiano - que fez emergir a educação escolar, marcada pela disciplina moderna, a qual é materializada por dispositivos como o controle do tempo e do espaço, a organização das forças, o clima de concorrência e de premiação discente e a ênfase nos castigos morais. Essa questão é lida nas seguintes obras: "Produção da escola/produção da sociedade: análise sócio-histórica de alguns momentos decisivos da evolução escolar no ocidente", do sociólogo André Petitat; "Arqueología de la escuela", dos sociólogos Julia Varela e Fernando Alvarez-Uría; e "A invenção da sala de aula: uma genealogia das formas de ensinar", dos historiadores Inés Dussel e Marcelo Caruso. Assim, nesses três livros procura-se constatar elementos comuns sobre o surgimento da escolarização, mas também perceber diferenças, especialmente aquelas vinculadas às fundamentações teóricas e aos recortes espaciais.

Palavras-chave: Reforma religiosa; Escolarização; Jesuíta; Protestante.

Abstract The present article maintains that the religious reforms constructed the birth of the western schooling from different Christian matrices - protestant and catholic. It is a historical displacement - in the foucaultian sense - that has made school education emerge, marked by modern discipline, which is materialized by devices such as time and space control, the organization of forces, the atmosphere of competition and student's awards, and em-

I Universidade do Estado de Santa Catarina - UDESC. Florianópolis/SC - Brasil. 
phasis on moral punishment. This issue is seen in the following works: "School production / societal production: socio-historical analysis of some decisive moments of school evolution in the West", by the sociologist André Petitat; "Archeology of the school", by sociologists Julia Varela and Fernando Alvarez-Uría; and "The Invention of the Classroom: A Genealogy of Teaching Forms", by historians Inés Dussel and Marcelo Caruso. Thus, in these three books we try to find common elements about the emergence of schooling, but also to perceive differences, especially those related to theoretical foundations and spatial cutouts. Key-words: Religious reform; Schooling; Jesuit; Protestant.

Resumen El presente artículo sostiene que las reformas religiosas construyeron el nacimiento de la escolarización occidental a partir de diferentes matrices cristianas - protestantes y católicas. Se trata de un desplazamiento histórico - en el sentido foucaultiano - que hizo emerger la educación escolar, marcada por la disciplina moderna, la cual es materializada por dispositivos como el control del tiempo y del espacio, la organización de las fuerzas, el clima de competencia y de el énfasis en los castigos morales. Esta cuestión se lee en las siguientes obras: "Producción de la escuela / producción de la sociedad: análisis sociohistórico de algunos momentos decisivos de la evolución escolar en el occidente", del sociólogo André Petitat; "Arqueología de la escuela", de los sociólogos Julia Varela y Fernando Alvarez-Uría; Y "La invención del aula: una genealogía de las formas de enseñar", de los historiadores Inés Dussel y Marcelo Caruso. Así, en estos tres libros se busca constatar elementos comunes sobre el surgimiento de la escolarización, pero también percibir diferencias, especialmente aquellas vinculadas a las fundaciones teóricas ya los recortes espaciales.

Palabras clave: Reforma religiosa; Escolarización; Jesuita; Protestante.

\section{INTRODUÇÃo}

As reformas religiosas do século XVI foram as parteiras da primeira modernidade. Em um momento em que, com a expansão ibérica, os continentes começavam a se globalizar, elas provocaram profunda fragmentação no espaço europeu e guerras de religião. Essa confessionalização da sociedade fez emergir um cristianismo mais racionalizado, representado por diferentes igrejas protestantes e pelo catolicismo tridentino, particularmente aquele praticado pela Companhia de Jesus. Esse deslocamento histórico - no sentido foucaultiano - merece ser lido para se compreender o mundo contemporâneo. Trata-se da análise de processo de longa duração que teve começos parciais desde o Quinhentos e se adensaram nos séculos seguintes, mas de forma dispersa. Entre os trabalhos que proporcionaram nova leitura da ruptura do medievo para a Idade Moderna, pode-se citar A Ética protestante e o espirito do capitalismo, de Max Weber (1983); O processo civilizatório, de Elias (1989); Vigiar e punir, de Michel Foucault (1993), e História social da família e da criança, de Philippe Ariès (1981).

Diferenciando-se do cristianismo medieval, luteranos, calvinistas e anglicanos investiram na criação de suas redes de instituições educativas, provocando uma onda inédita 
de alfabetização, que concorria para dar consistência às práticas religiosas de seus fiéis. A Igreja Católica também se armou, criando escolas paroquiais e, sobretudo, uma rede de colégios jesuíticos que se difundiram no espaço europeu católico, no continente asiático e no Novo Mundo. Os estabelecimentos de ensino da Companhia de Jesus foram unificados, em 1599, por meio da instituição da Ratio Studiorum - conjunto de regras escolares jesuíticas que se converteram no currículo fundador da escolarização católica a partir da Idade Moderna. Assim, as reformas religiosas desencadeadas pela publicação das 95 teses de Lutero, em 1517, construíram o nascimento da escolarização ocidental a partir de diferentes matrizes cristãs - protestantes e católica. Trata-se de um divortium aquarum, que fez emergir a escolarização no espaço ocidental, marcada pela disciplina moderna e materializada por dispositivos como o controle do tempo, o esquadrinhamento do espaço, a organização das forças, o clima de concorrência e de premiação discente e a ênfase nos castigos morais.

Neste trabalho, o nascimento da escolarização ocidental é lido em três obras históricas publicadas no tempo presente na Europa e na América Latina, quais sejam: "Produção da escola/produção da sociedade: análise sócio-histórica de alguns momentos decisivos da evolução escolar no ocidente", do sociólogo André Petitat (1994); “Arqueología de la escuela", dos sociólogos Julia Varela e Fernando Alvarez-Uría (1991); e "A invenção da sala de aula: uma genealogia das formas de ensinar", dos historiadores Inés Dussel e Marcelo Caruso (2003). Certamente esses trabalhos estão entre os mais instigantes e consistentes publicados no espaço euro-americano que se propõem a pensar a escolarização ocidental na clave da longa duração, situando os seus começos parciais na conjunção das reformas religiosas do século XVI. Esta reflexão historiográfica, portanto, examina o surgimento da escolarização ocidental, procurando constatar elementos comuns de análise dos três livros, mas também perceber diferenças, especialmente aquelas vinculadas às fundamentações teóricas e aos recortes socioespaciais.

Para tanto, vale-se do conceito de representação enunciado por Chartier (2002) que, apoiando-se em Pierre Bourdieu, Michel de Certeau, e particularmente em Louis Marin, confere ao conceito de apropriação um duplo sentido: por um lado, é a "presentificação" do ausente ou do que já passou; mas, por outro, trata-se de uma "reapresentação mais ou menos adequada de algo já dado, apresentado e conhecido como 'o real"” (CARVALHO e HANSEN, 1996, p. 12). No primeiro sentido, "la representación hace ver el 'objeto ausente' (cosa, concepto o persona) substituyéndolo por una 'imagen capaz' de representarlo adequadamente. Representar es pues dar a conocer las cosas indirectamente" (CHARTIER, 2000, p. 75). Representação é também a construção social de uma coisa ou de uma pessoa, como esclarece Chartier (2000, p. 85):

Más allá de este primer uso, historicamente localizado, la noción de representatión se há cargado de una pertinencia más amplia, al designar al conjunto de las formas teatralizadas y 'estilizadas' (según las palabras de Max Weber) gracias a las cuales los indivíduos, los grupos sociales, los poderes, construyen y proponen una imagen de ellos mismos. [...] Entendido de este modo, el concepto de representación lleva a pensar en el mundo social o en el ejercicio del poder 
como un sistema de relaciones. Las modalidades de presentación de un grupo social o de una autoridad están, ciertamente, gobernadas por las propiedades sociales de este grupo social o los recursos propios de este poder.

No campo historiográfico, o uso do conceito de representação implica suspender a noção de mentalidade como um denominador comum de uma coletividade e compreender as formas singulares de uso dos bens culturais por indivíduos ou grupos sociais. Segundo Chartier (2002, p. 176), fazer história com a ferramenta conceitual de representação significa "reconhecer que as realidades passadas não são acessíveis, na maioria das vezes, senão através de textos que pretendiam organizá-las, descrevê-las, prescrevê-las ou proscrevê-las". A história-conhecimento é sempre uma representação do passado construída pelas lentes do historiador que a escreve e, geralmente, por documentos-monumentos específicos e parciais. Neste ensaio historiográfico, portanto, procura-se analisar como três textos históricos construíram a sua compreensão do nascimento da escolarização ocidental a partir das reformas religiosas do Quinhentos.

\section{O SURGIMENTO DO DUALISMO ESCOLAR}

O livro de Petitat (1994), publicado originalmente em língua francesa em 1982 e traduzido para o português doze anos depois, tem como subtítulo "análise sócio-histórica de alguns momentos decisivos da evolução escolar no ocidente". O primeiro "momento decisivo" da escolarização apontado pelo sociólogo canadense foi a instituição e disseminação dos colégios a partir do século XVI, considerado um fato marcante na história da escolarização. Os colégios das congregações católicas, das igrejas protestantes e aqueles vinculados às universidades tinham, segundo ele, "semelhança institucional" pelo fato de terem em comum dispositivos escolares tais como "concentração dos cursos dentro dos estabelecimentos, gradação sistemática das matérias, programa centrado no latim e no grego, controle contínuo dos conteúdos adquiridos, supervisão e disciplina" (PETITAT, 1994, p. 76). Outra característica notável nos colégios é a sua permanência ao longo de praticamente toda a Idade Moderna, pois, somente em meados do Século das Luzes passaram a ser alvo de críticas, vindas dos que defendiam o ensino das línguas nacionais e dos saberes das Ciências Naturais e daqueles que propunham novas metodologias de aprendizagem.

Petitat (1994) constata as "profundas diferenças" entre as práticas educativas medievais e os colégios modernos. O deslocamento histórico começou a se processar nos hospitia, alojamentos para estudantes que frequentavam as Faculdades de Artes, mantidos por nobres ou eclesiásticos enriquecidos. Em Paris, em princípios do século XIV, os hospitia começaram a se transformar em estabelecimentos de ensino onde os estudantes recebiam aulas de recuperação. Aos poucos os estudantes começaram a abandonar as aulas avulsas nas Faculdades de Artes e a preferir o ensino institucionalizado nos emergentes colégios. A esse respeito, o autor da obra em tela conclui: 
Assim, à dispersão dos ensinos individuais sucedeu um agrupamento de estudantes e de professores em um certo número de estabelecimentos. Importantes transformações no ensino acompanham este movimento de concentração, referentes ao controle exercido sobre os estudantes, às matérias ensinadas e à criação de graus e classes (PETITAT, 1994, p. 77, grifo do autor).

Houve, portanto, uma transformação marcante em relação ao disciplinamento dos estudantes, que passaram a ser submetidos a um controle permanente e a uma sequenciação dos saberes.

A introdução das séries e das classes escolares deu-se também nos colégios organizados pelos Irmãos de Vida Comum, nos Países Baixos, no final do século XV, mas se disseminou e se aperfeiçoou nos colégios protestantes e católicos da centúria seguinte. Entre os Irmãos de Vida Comum inicialmente havia somente três ou quatro classes, mas depois foram desdobradas em seis ou sete classes sucessivas. Mélanchton, colaborador de Martinho Lutero, propôs um plano de reforma do ensino, em 1528, em que dividia o ensino em três classes: aprendizagem de leitura e escrita, de gramática latina e de lógica. Baduel, que era ligado a Sturm e de Calvino e foi o organizador do Colégio de Nîmes, afirmava, em 1549, que "a escola se dividirá em classes de acordo com a idade e o desenvolvimento dos alunos. $\mathrm{O}$ ensino das crianças pequenas será diferente daquele dos adolescentes, e ambos terão seu início, sua marcha progressiva e seu final" (apud PETITAT, 1994, p. 79). Os jesuítas transmitiram essas experiências em relação à sequenciação de conteúdos e as burilaram, inscrevendo-as na Ratio studiorum.

Petitat (1994) aponta o fosso entre as Faculdades de Artes da Idade Média e os colégios modernos, indicando que ele se processou do século XIV ao XVI. Defende que as novas experiências pedagógicas foram implementadas efetivamente nos colégios das igrejas protestantes e da Igreja Católica, pois elas encontraram mais resistência nos colégios universitários, devido ao peso de sua tradição medieval. Na opinião do sociólogo canadense, os principais teóricos e propagadores do novo ordenamento educacional estão entre os homens das Reformas Religiosas, que colocaram a escola como uma das principais estratégias da concorrência religiosa no início da Idade Moderna. Nesse sentido, ele cita a frase lapidar "as igrejas não podem prosperar sem escolas", formulada pelo reformador Mélanchton, que dá o tom do novo momento histórico no Ocidente. Entre os reformadores do ensino, os calvinistas e jesuítas ganham realce - sendo contemplados com subcapítulos específicos, em que são citados e analisados o modelar Colégio de Genebra, fundado, em 1559, por João Calvino e Teodoro de Bèze e a Ratio studiorum.

A obra "Produção da escola/produção da sociedade" procura identificar e compreender os mecanismos que concorreram para a manufatura da nova pedagogia nos colégios modernos. Em primeiro lugar, essas instituições escolares se diferenciavam pela introdução do tempo linear e cronológico, que já era utilizado nas cidades mercantis desde o século XIV. Petitat (1994) aborda com muita clareza e propriedade a presença do cronológico nas instituições escolares ocidentais na Idade Moderna. E afirma: "A transformação que mais nos chama a atenção está na instituição progressiva de uma divisão regular do horário, substituindo o ho- 
rário irregular da Igreja" (PETITAT, 1994, p. 91). Os minutos e as horas passam a fragmentar o cotidiano das escolas, de forma que o conhecimento escolar deve ser adequado a tempos delimitados, ao contrário da Idade Média, quando o aprendizado nas Faculdades de Artes era flexível, de acordo com o ritmo individual do estudante. A marcação cronológica do tempo é o dispositivo que permite pensar a divisão dos horários, das classes e dos graus, bem como, a ideia de progressão escolar e de classificação e premiação dos alunos.

Os colégios modernos também se diferenciavam das Faculdades de Artes medievais pelo fato de sequestrarem os alunos e os submeterem a uma quarentena - para utilizar a expressão feliz de Ariès (1981). O sociólogo canadense afirma que a segregação entre adultos e "crianças" é um dos princípios da Pedagogia Moderna, mas sublinha que a nova categoria inventada no início da Idade Moderna é a adolescência. Grosso modo, no período medieval não havia divisão de idade no mundo social nem nas escolas catedrais e universidades, de forma que estudantes de diferentes idades conviviam e aprendiam lado a lado. No entanto, Petitat (1994) chama a atenção para o caráter de classe na construção da adolescência: "Mas, se no século 16 já existe a separação entre o adulto e o adolescente, ela está confinada aos colégios e concerne, pois, em primeiro lugar, às camadas sociais superiores. $\mathrm{O}$ aprendiz e o jovem trabalhador ainda compartilham da vida dos mais velhos" (PETITAT, 1994, p. 91). Os adolescentes passam a ser confinados num regime especial, mais particularmente nos internatos, que cortavam ainda mais os seus laços comunitários e culturais.

No interior dos colégios, foi colocada em marcha uma prática estranha à pedagogia medieval: os trabalhos escritos, fossem eles exercícios, deveres ou provas. No medievo predominavam as disputas orais, em que mestres e discípulos se desafiavam de forma verbal, geralmente em torno de questões teológicas. Nessa direção, Petitat (1994, p. 81) conclui: "A composição latina representa o exemplo modelar destas novas práticas, sem qualquer dúvida encorajadas pelo desenvolvimento da imprensa". A lógica dos exercícios estava articulada com a nova configuração espaço-temporal e concorria para o incitamento ao trabalho regular, que desqualificava o ócio, a preguiça e a mendicância. O sociólogo canadense referencia o trabalho clássico de Weber (1983) para mostrar que a perda de tempo passa a ser considerada o mais mortal dos pecados. No entanto, a exaltação do trabalho é constatada entre todos os reformadores religiosos; para o catolicismo tridentino, a palavra trabalho foi ressignificada, deixando de ter o sentido de punição e sofrimento.

Ademais, nos colégios modernos passou-se a operar um novo recorte e organização dos saberes, que privilegiava "o aprendizado correto da gramática latina e grega" e o estudo dos autores da Antiguidade Clássica, em especial Cícero, considerado o modelo de clareza e perfeição. Essa mudança é verificada nas propostas educativas do pedagogo luterano Mélanchton, no currículo dos colégios calvinistas e na Ratio studiorum, da Companhia de Jesus. Segundo Petitat (1994), o destaque dado pelos colégios ao latim ocorreu no momento em que essa língua deixou de ser utilizada nos negócios e na administração, contudo mantendo-se nas igrejas e nos círculos letrados universitários. A predominância do latim e do grego nos colégios permaneceu - no caso francês - no mínimo até a Revolução Francesa, apesar da crítica formulada por vários pensadores no século XVIII e da introdução 
de disciplinas modernas em alguns colégios como os dos jesuítas e, principalmente, dos oratorianos - mais abertos aos ares regalistas e aos saberes modernos.

Nos seus colégios, os padres jesuítas também operaram um recorte específico sobre os textos dos autores da Antiguidade Clássica, procurando despaganizá-los para ajudarem a incutir a fé católica tridentina. Petitat (1994, p. 82) afirma que "os jesuítas truncam os textos e tomam parte ativa no surgimento de uma literatura de 'trechos escolhidos', a qual se presta admiravelmente bem aos múltiplos exercícios e ao aprendizado formal das línguas antigas". Os padres-professores buscavam afastar os seus alunos da literatura corrente na sua época, pontuada por críticas à Igreja Católica advindas da conjunção das Reformas Religiosas e das guerras de religião. A ressignificação jesuítica da cultura da Antiguidade Clássica, depois de realizada nos colégios da Companhia de Jesus na segunda metade do século XVI, foi inscrita na Ratio studiorum, que também tinha a função de homogeneizar conteúdos culturais.

Petitat (1994) debruça-se na compreensão da seleção dos estudos clássicos como eixo estruturador do currículo dos colégios modernos, pois constata que somente um quarto dos seus alunos - ou seja, aqueles que ingressam nos cursos superiores ou os futuros professores de escolas elementares latinas ou colégios - utilizavam profissionalmente o conhecimento da língua latina e grega. Conclui que a maioria dos alunos buscava as "belas-letras" como distinção estética, ao lado das maneiras civilizadas, que passaram a ser desejadas pelas elites burguesas e nobres. O sucesso do livro De civilitate morum puerilium, de Erasmo de Rotterdam, publicado em 1530, e que teve 80 edições e 14 traduções, é oportunamente lembrado e foi um sintoma da mudança de sensibilidade entre o Medievo e a Idade Moderna. Por sua vez, Petitat constata que a civilidade das elites foi levada posteriormente às classes populares, como é o caso do manual de civilidade, produzido por João Batista de La Salle, no início do século XVIII, para ser utilizado nas escolas elementares de caridade.

A argumentação caminha no sentido de constatar conexões entre os colégios modernos e a burguesia emergente, que procura se aproximar da nobreza por meio da aquisição de seu capital cultural e marcar posição em relação às classes populares. Trata-se de "gente graúda" - tradução de peuple gras -, representada especialmente pelos grandes comerciantes, letrados, funcionários públicos e profissionais liberais, que despreza o trabalho manual. A nobreza também aprendia as "belas-letras" nos colégios, mas complementava a sua formação cavalheiresca com preceptores e, posteriormente, nas academias. Há uma matização muito pertinente em relação ao estrato nobiliárquico: na França os nobres menos abastados estudavam em colégios menores, enquanto a alta nobreza frequentava os colégios de elite - como os colégios La Flèche, Clermont e de Juilly. A cultura humanista dos colégios não era suficiente para enobrecer a burguesia, mas necessária para aqueles que aspiravam à "nobreza de veste".

Petitat (1994) constata também a emergência de escolas elementares de caridade na segunda metade do século XVII, dirigidas pelo Abade Démia e sobretudo pelos lassalistas. O método das escolas dirigidas por Jean Batiste de La Salle era muito próximo da Ratio studiorum, pelo fato de procurar educar por meio de estratégias pedagógicas modernas, 
como o incitamento do corpo docente ao trabalho regular, a emulação, o uso de castigos morais e físicos, a implementação de exercícios de penitência. No entanto, as escolas lassalistas substituíram as línguas clássicas pelo francês e também ensinavam rudimentos de aritmética. ${ }^{1}$ A emergência das escolas elementares de caridade estava ligada aos motins e revoltas que pulularam na primeira metade do século XVII devido à aguda crise econômica que passava a Europa, que associou ainda mais a imagem da pobreza à da violência.

Enfim, ao cotejar as pequenas classes dos colégios e as escolas elementares de caridade na obra de "petitatiana", conclui-se que há pontos de convergência, especialmente em relação aos novos mecanismos de controle escolar estranhos ao mundo medieval. No entanto, há também o estabelecimento de um dualismo escolar, em que os colégios modernos, marcados pela cultura humanista distintiva, preparavam para o ingresso das elites nos cursos superiores, enquanto as escolas elementares de caridade, cujo aprendizagem centrava-se na língua francesa e em rudimentos aritméticos, concorriam, sobremaneira, para a moralização e o controle das classes trabalhadoras.

\section{A EMERGÊNCIA DE TRÊS MODOS DE EDUCAÇÃo}

O livro Arqueología de la escuela (VARELA e ÁLVAREZ-URÍA, 1991) também considera que, a partir do século XVI, emergiram novas práticas educativas que se diferenciaram, substancialmente, daquelas realizadas na Idade Média. Essa obra coloca o foco sobre os novos dispositivos de intervenção da Igreja Católica para fazer frente aos Estados administrativos modernos e, sobretudo, para combater as igrejas protestantes que, desde o cisma iniciado por Martinho Lutero, se disseminaram no território europeu. Eles concebem que as Reformas Religiosas e as guerras de religião foram a pedra de toque na conjunção social pós-medieval, pois acreditam que "el fanatismo religioso es una de las claves de la modernidad" (VARELA e ÁLVAREZ-URÍA, 1991, p. 9). Tanto as igrejas protestantes como a Igreja Católica passaram a investir na produção de sujeitos fiéis às suas doutrinas, privilegiando os indivíduos de tenra idade, que poderiam ser moldados com mais facilidade e eficácia, principalmente por meio da criação de instituições educativas.

Especialmente após o Concílio de Trento, a Igreja Católica passou por uma reestruturação significativa, procurando redefinir sua posição teológica, pastoral e litúrgica. O catolicismo tridentino produziu diversificadas estratégias de conquista e de manutenção da fé ortodoxa, entre as quais a criação de devoções modernas, a fundação de santuários, a confissão, a direção espiritual, a criação de instituições escolares, a elaboração de catecismos, a definição do Index Librorum Prohibitorum, a retomada das práticas inquisitoriais. Assim como as confissões protestantes, a Igreja Católica investiu em várias frentes educativas, que passaram a atender às classes sociais de forma diferenciada e contribuíram para impedir o avanço do cisma moderno. Os reformadores católicos atuaram como preceptores dos filhos da nobreza cortesã, como fundadores de colégios para as elites burguesas e de instituições assistenciais e de caridade para as classes populares. Para realizar essa tarefa ful-

$\underline{1}$ Sobre as escolas lassalistas, consultar Fiévet (2001). 
cral, foram criadas novas congregações católicas, com devoção e religiosidade modernas, entre as quais se destacou a Companhia de Jesus - a "tropa avançada da Contrarreforma".

Os sociólogos espanhóis identificam a emergência da infância na Idade Moderna ligada a práticas familiares, modos de educação, classes sociais e gêneros. Apoiados em Ariès (1981), constatam que, entre o Renascimento e as Reformas Religiosas, foi brotando uma nova atitude em relação à "infância", tematizada pelos humanistas e reformistas religiosos. Chamam a atenção de que não se tratava de uma etapa cronológica precisa como se conhece nos dias atuais, mas de uma distinção do mundo adulto, que era denominada "juventude" ou "mocidade". A construção social da infância também é percebida nas pinturas da corte espanhola da Idade Moderna, particularmente nos quadros de Velázquez sobre os filhos da aristocracia. Segundo os autores, a configuração da juventude ou mocidade nesse momento histórico serviu de base para os desdobramentos posteriores da "infância" realizados por Rousseau (1968) e para o nascimento da figura do bebê no século XIX.

No entanto, Varela e Alvarez-Uría (1991) sublinham que essa nova sensibilidade em relação à infância se colocou, inicialmente, entre as crianças das classes privilegiadas e entre os meninos. Argumentam que, assim como na atualidade, na Idade Moderna existiram diferentes infâncias, que eram produzidas por diversificados modos de educação vinculados aos seus estamentos sociais. À luz dos trabalhos de Elias $(1989,1993)$, eles desnaturalizam as camadas aristocráticas, ou seja, diferenciam a nobreza militar do Medievo da nobreza cortesã da Idade Moderna, que era educada nas armas e nas letras por preceptores domésticos para ocupar postos de comando nos Estados absolutistas. Chamam a atenção para o surgimento de manuais de civilidade para essa nova nobreza, entre os quais $\mathrm{De}$ civilitate morum puerilium, escrito por Erasmo de Rotterdam, em 1530, e que se disseminou em vários países europeus. ${ }^{2} \mathrm{Na}$ Espanha, além de ser introduzido na nobre arte das armas, Felipe II foi o primeiro infante a aprender o latim e a ter gosto pelas obras clássicas. Grosso modo, a burguesia emergente e a nobreza provinciana foram educadas nos colégios, que tiveram um grande florescimento nessa época no mundo ocidental. Na Espanha, a grande maioria dos colégios foi instituída pela Companhia de Jesus, que colocava em marcha dispositivos disciplinares inscritos na Ratio studiorum. Tanto nas cortes modernas como nos colégios, a infância masculina foi a primeira a ser construída, viabilizando a preparação dos homens para a vida pública.

A educação da infância das classes populares pertencia a outro mundo social, pois se constituía de rudimentos das letras, doutrina cristã e aprendizagem de ofícios e era realizada em casas de recolhimento e hospitais. Os sociólogos espanhóis afirmam que Ariès (1981) não deu a devida importância aos dispositivos disciplinares utilizados no recolhimento e moralização das crianças das classes desfavorecidas e comparam:

\footnotetext{
2 Varela (1983) afirma que o "Plano de estudos" de Erasmo de Rotterdam teve influência na educação jesuítica e nas obras pedagógicas de Vives.
} 
La infancia "rica" va a ser ciertamente gobernada, pero su sumisión a la autoridad pedagógica y a los reglamentos constituye un paso para asumir "mejor" más tarde funciones de gobierno. La infancia pobre, por el contrario, no recibirá tantas atenciones siendo los hospitales, los hospicios y otros espacios de corrección los primeros centros-piloto destinados a modelarla (VARELA e ALVAREZ-URÍA, 1991, p. 25).

Contudo, na Espanha seiscentista eles dão destaque aos esculápios, ${ }^{3}$ que tiveram um projeto educativo direcionado para os meninos pobres, baseando-se na Ratio studiorum dos jesuítas. O sistema disciplinar dos esculápios era mais severo e rude e até os prêmios de suas escolas - estampas e livrinhos piedosos - eram menos refinados do que aqueles dos colégios jesuíticos (VARELA e ALVAREZ-URÍA, 1991).

Arqueología de la escuela procura mostrar que os modos de educação na Espanha da Contrarreforma não se diferenciaram somente pelo conteúdo cultural que recortavam e transmitiam, mas também pelas formas distintas de disciplinamento corporal específicas de cada estamento social. Há, definitivamente, uma assimetria entre as classes populares e as elites, mas se verifica também uma matização nas classes abastadas entre a nobreza da corte e a burguesia, como sintetizam os sociólogos espanhóis:

La recogida y educación de los niños pobres en instituciones a las que son destinados poco tiene que ver no sólo con la educación de Príncipe niño sino también con la de los colegiales que además de dedicarse al estudio de materias literarias (gramática, retórica, dialéctica) vedadas para los pobres y al de distintas lenguas entre las que predomina el latín, se entretienen com juegos y espectáculos cultos y adquieren cortesanas maneras mediante la danza, la esgrima, la equitación y otros ejercicios de marca que les proporcionarán lo que Pierre Bourdieu denomina una hexis corporal en consonancia com su categoria social. Pero no se trata únicamente de diferencias de contenidos y actividades sino que la dureza del encierro, el rigor de los castigos, el sometimiento a las órdenes, el distanciamento de la autoridad, y la autopercepción que se les inculca son el fruto de la diferencia abismal que existe entre los preceptores domésticos, los colegios y "las escuelas de primeras letras" destinadas a los hijos de los pobres (VARELA e ALVAREZ-URÍA, 1991, p. 31).

Na sua genealogia da escolarização, Varela e Alvarez-Uría (1991) flagram o espaço conventual como um dispositivo disciplinar e o principal sinal arquitetural das instituições educativas pós-medievais. Os espaços fechados modernos, como colégios, albergues, casas de misericórdia, hospícios, seminários, que se disseminaram a partir do século XVI, têm uma lógica ordenadora e reguladora, que faz parte da "nova gestão das populações".

3 Os esculápios foram fundados por São José de Calasanz em 1597, a partir de uma escola gratuita para meninos pobres na cidade de Roma, e oficializados pelo papa Paulo V em 1622. Chegaram à Catalunha em 1648 e se disseminaram na Espanha a partir da segunda metade do século XVII (RUIZ, 1998, p. 126-7). 
Ariès (1981) inspirou essa reflexão por ter constatado que, na Idade Moderna, a aprendizagem passou a ser mediada pelas instituições escolares que enclausuravam as crianças, separando-as dos adultos. No entanto, essas instituições educativas são cuidadosamente diferenciadas em relação às classes sociais, pois os filhos das classes aristocráticas passavam por "enclausuramento moral", enquanto as crianças pobres eram submetidas a rigoroso e rude isolamento disciplinar. Essas práticas de sequestro se colocaram de forma explícita nos colégios que educaram, sobremaneira, a burguesia emergente, a qual se tornou a classe social vitoriosa no mundo contemporâneo.

A descontinuidade entre as práticas educativas medievais e os colégios modernos pode ser verificada pelo cotejo da função do professor em cada uma dessas instituições educativas. Apoiados nos estudos históricos de Durkheim (1995), os sociólogos espanhóis contrapõem o mestre das universidades e instituições educativas medievais, que se pautava pela posse e transmissão de determinados saberes, ao professor jesuíta, que deveria ser "um modelo de virtude". O primeiro ocupava a cátedra de um grande auditório, cujo público estudantil era formado por diferentes idades e, após a sua lição, não tinha mais compromissos com o seu alunado, enquanto o segundo, além de transmitir conhecimento recortado e ressignificado pelo catolicismo tridentino, tinha a missão de regular e moralizar a vida escolar e social dos alunos. O professor jesuíta adotava um conjunto de dispositivos disciplinares - estranhos para o cotidiano educativo medieval -, entre os quais o controle do tempo, o esquadrinhamento do espaço, o incitamento ao exercício permanente e escrito, a organização da emulação, a classificação e premiação entre os alunos e a substituição dos castigos físicos pela vigilância amorosa. Essas práticas disciplinares levadas a cabo pelos discípulos de Inácio de Loyola foram ensaiadas inicialmente nos colégios jesuíticos e, posteriormente, inscritas na Ratio studiorum (DALLABRIDA, 2001).

A implantação dos colégios jesuíticos concorreu para a destruição e desvalorização de formas autônomas existentes nas instituições educativas medievais, como as universidades e as corporações de ofício - onde havia uma relação mestre-discípulo. Os autores de Arqueología de la escuela sugerem que havia uma estrutura comum entre as instituições educativas medievais e as oficinas artesanais, assim como, entre os colégios jesuíticos e as manufaturas modernas. Na Espanha, a mudança dessa configuração educativa começou a se colocar com a criação da Universidade de Alcalá de Henares, promovida pelo cardeal Cisneros, e se dilatou no século XVI nas universidades reformadas e colégios jesuíticos.

\section{O NASCIMENTO DA ESCOLA ELEMENTAR}

A obra "A invenção da sala de aula" (DUSSEL e CARUSO, 2003) lança um olhar genealógico - no sentido foucaultiano - sobre a escola elementar ou primária. Apoiada em Ariès (1981), inicia desnaturalizando essa instituição escolar ao constatar que, na Idade Média, os conhecimentos elementares eram ensinados nas famílias ou na aprendizagem de um ofício e a escolarização era feita nas universidades. Por isso, acredita que "a escola 
elementar é uma invenção moderna" (DUSSEL e CARUSO, 2003, p. 48), sendo plasmada por diferentes processos escolares de corte disciplinar. Assim, no final da Idade Média, algumas pensões de estudantes se transformam numa espécie de internato, ritmado por dispositivos de controle do tempo e do espaço e locais de aprendizagem. No entanto, as reformas religiosas do século XVI foram, efetivamente, o fenômeno desencadeador da escolarização, de sorte que a religião cristã fragmentada atuou como parteira dessa inovadora forma de educação. O primeiro e decisivo passo foi dado por Martinho Lutero, em 1517, ao promover o estabelecimento da Igreja Luterana e estimular outros cismas modernos como o calvinismo e o anglicanismo.

A partir de premissas teológicas, Lutero traduziu a Bíblia do latim para a língua materna e estimulou a criação de escolas que ensinassem os novos fiéis a ler - mas não a escrever, uma prática própria da educação superior - a palavra divina, desencadeando uma onda de alfabetização no espaço luterano europeu. As outras confissões protestantes também passaram a adotar a escolarização como uma estratégia catequética eficiente e o catolicismo reformado, que teve como referência o Concílio de Trento, também investiu na escolarização por meio da criação de escolas paroquiais e, sobretudo, dos colégios da Companhia de Jesus, que tiveram expansão global na segunda metade do século XVI. Em clima de concorrência estabelecida pelas Reformas Religiosas, as razões cristãs da escolarização ocidental são condensadas por Dussel e Caruso (2003, p. 62-3) da seguinte forma:

\footnotetext{
Em síntese, para produzir uma posição católica ou protestante de profunda convicção, ambas as igrejas encontraram um espaço em desenvolvimento ao qual dedicaram atenção, cuidados, programas e controle: a escola. Para governar os fiéis sob a ameaça da existência de outra confissão, foi necessário um processo de afirmação de certas disposições, atitudes e ideias. Em função de suas características de duração, perseverança e constância, o processo de escolarização aparecia como forma maciça ideal para atingir esse objetivo.
}

Inspirados em Foucault, os historiadores argentinos indicam o problema do governo das crianças que se colocou, no século XVI, como questão fulcral pela pedagogia. O modelo usado pelas igrejas foi o pastorado, que tinha longa tradição religiosa, de modo que a turma de alunos passou a ser vista como um coletivo a ser levado para o "bom" caminho. Na perspectiva foucaultiana, o poder pastoral não é praticado em relação a um espaço, mas exercido em relação a um rebanho ou a um grupo de pessoas com o intuito de ser conduzido ao mesmo tempo de forma coletiva e individual. Dussel e Caruso (2003, p. 65) esclarecem que "este objetivo ambicioso exigia técnicas que mantivessem o rebanho como totalidade e, ao mesmo tempo, técnicas que se ocupassem de cada membro do rebanho. Foucault identificou essa orientação como um poder dedicado 'a todos e a cada um' (em latim, omnes et singulatim)". A partir desse binômio são analisados dois modelos pedagógicos que enfatizam, respectivamente, o lado grupal da sala de aula - o método global de Comênio - e o lado individualizador da sala de aula - o método dos jesuítas. 
Jan Amos Comênio foi um reformador protestante que, com o propósito de divulgar a Bíblia, escreveu várias obras educativas, entre as quais A Didactica Magna, considerada o discurso fundador da didática moderna. Nessa obra, Comênio fundamenta a sua pedagogia na natureza como criação divina e prescreve a sala de aula "tradicional", tendo no professor o agente central do ensino, que colocava o problema da captação da atenção dos alunos. Ele faz uma defesa enfática da unificação do método global ou frontal, que utilizava estratégias da pregação religiosa. Dussel e Caruso (2003, p. 73) asseveram que "não apenas se unificava o método, mas também o docente aparecia com toda sua centralidade, como encarnação de sua unificação". Mesmo com a utilização de monitores - escolhidos entre os alunos mais capazes ou hábeis - Comênio insistia no papel central do professor no processo de ensino, considerado o sol que a todos ilumina. No método global de Comênio, portanto, o fulcro era a condução da sala de aula pelo professor não de uma forma externa e individual, mas por meio da obediência consentida e coletiva dos alunos. Assim, o método global comeniano colocava o foco no omnis.

De outra parte, a pedagogia jesuítica acentuou mais o lado individualizador do poder pastoral na escola. Criada como uma das principais estratégias da reforma católica, a Companhia de Jesus foi a primeira congregação global e docente da Igreja Católica, que unificou a sua prática pedagógica por meio da Ratio Studiorum - tornada o método oficial dos jesuítas em 1599. Dussel e Caruso (2003, p. 78) assinalam que "dentro da estratégia do poder pastoral, a pedagogia jesuíta deu destaque à questão da atenção individual, provavelmente derivada da prática da confissão e absolvição, tão criticada pelos reformadores protestantes". Deve-se considerar que as salas de aulas dos colégios da Companhia de Jesus comportavam centenas de alunos, que deveriam ser governados de forma coletiva, mas, de modo especial, por meio de estratégias de individualização. Para isso, nos educandários jesuítas havia tanto a ação dos professores, que faziam preleções, como a intervenção dos monitores, que tinham uma hierarquia, de sorte que havia uma multiplicidade de olhares a vigiar o corpo discente. De outra parte, os professores jesuítas foram dos primeiros docentes a introduzir as notas escolares, que permitiam a classificação e premiação dos alunos e estimulavam a competição permanente entre eles. O método dos jesuítas, portanto, era constituído por dispositivos disciplinares que estimulavam sobremaneira o singulatim.

Os historiadores argentinos defendem que os colégios jesuítas não eram direcionados às classes populares, que no mundo católico eram clientela das escolas lassalistas, criadas, desde o final do século XVII, pelo padre francês João Batista de La Salle. Essa rede de escolas elementares foi construída com doações de parte das classes abastadas e, principalmente, pela parceria entre os Irmãos das Escolas Cristãs - associação criada por La Salle - com municípios franceses. Um dos principais diferenciais do ensino das escolas lassalistas foi a adoção da língua materna, que pautaria os currículos de outras congregações católicas bem como, posteriormente, das escolas elementares públicas. No tocante às estratégias didáticas, La Salle adotou o método global, apropriando-se em boa medida dos dispositivos disciplinares prescritos na Ratio Studiorum dos jesuítas, como o controle do tempo e o esquadrinhamento do espaço. A individualização escolar era materializada por 
meio de um controle minucioso do corpo e da vida dos estudantes, ritmados pelo tempo cronológico, que Dussel e Caruso (2003, p. 86) conceituam como "pedagogia do detalhe" - conceito foucaultiano identificado nas escolas lassalistas. Dessa forma, La Salle produziu uma escolarização híbrida, apropriando-se a um só tempo da individualização dos alunos - marcante no método jesuítico - e o método global que se disseminava nas escolas protestantes e católicas.

No entanto, é importante destacar que o poder pastoral previsto na pedagogia lassalista não era restrito ao corpo discente, mas era aplicado também aos professores. Aliás, os Irmãos das Escolas Cristãs se distinguiram no campo das congregações católicas pela preocupação com a formação do seu corpo docente. Na Ratio Studiorum os jesuítas já prescreviam condutas para os professores dos seus colégios, mas os irmãos lassalistas aprimoraram e detalharam essa preocupação pedagógica. Dussel e Caruso (2003, p. 85) constatam, de forma oportuna, o investimento da pedagogia lassalista em relação ao corpo docente, afirmando:

\footnotetext{
La Salle escreveu um Manual para os professores de sua ordem, que imediatamente se transformou em texto de orientação da pedagogia elementar. A Conduta das Escolas Cristãs, que começou a ser escrita em 1695 e foi finalmente publicada em 1720, um ano depois da morte de La Salle, incluía três partes: a primeira detalhava tudo o que devia ser feito desde o momento em que a escola abria até o seu fechamento; a segunda, os meios necessários e úteis para manter a ordem na sala de aula; e a terceira definia critérios para a inspeção das escolas e a formação de professores.
}

No tocante à era das reformas religiosas, o livro "A invenção da sala de aula", à maneira genealógica foucaultiana, procura compreender, precipuamente, o nascimento da escola elementar ou primária. Para tanto, busca as peças da maquinaria escolar lassalista no discurso pedagógico de Comênio sobre o método global e na experiência educativa dos jesuítas, de sorte que, respectivamente, havia uma ênfase na obediência pensada e coletiva e nos dispositivos de individualização. Assim, La Salle faz uma síntese, parindo a escola elementar que passou a ser o modelo na pedagogia católica e, mutatis mutandis, foi apropriada pela escola primária do sistema público de ensino.

\section{Considerações finais}

Apesar de terem referenciais teóricos e fontes documentais diferentes, as obras em análise têm parentesco histórico acerca da representação da escolarização na Idade Moderna. Deixam clara a descontinuidade entre as práticas educativas medievais e os colégios modernos e escolas elementares de caridade, como parte integrante da conjunção social de transição para o mundo pós-medieval. E percebem que as instituições educativas estabelecidas pelas Reformas Religiosas foram formatadas pela disciplina moderna - no sentido foucaultiano. Nos colégios foram adotados dispositivos disciplinares que procu-

Comunicações $\mid$ Piracicaba $\mid$ v. $25 \mid$ n. $2 \mid$ p. 207-223| maio-ago. 2018 
ravam proporcionar o controle escolar dos alunos, conectados com as novas formas de "governo" em várias instituições sociais e nos Estados absolutistas. E pensam essa transformação significativa nessas instituições educativas como um novo modelo de gestão dos indivíduos, criando imagens sugestivas para visualizá-la. Esses estudos, portanto, fazem parte da tradição historiográfica que concebem as escolas como instituições produtoras de sujeitos, geralmente contribuindo para a reprodução social.

Pelo fato de ter privilegiado a área francófona, Petitat (1994) dá destaque aos colégios calvinistas, especialmente aquele de Genebra, e à rede de colégios da Companhia de Jesus. Sublinha também que os principais educadores e propagadores da nova pedagogia foram homens vinculados às Reformas Religiosas. Constata a existência, durante a Idade Moderna, do dualismo escolar, contrapondo os colégios, frequentados pelas classes privilegiadas, às escolas elementares de caridade, cuja população escolar era formada pelas classes populares urbanas. O sociólogo canadense acredita que o disciplinamento corporal era semelhante nas duas redes escolares e que a diferenciação se dava em relação à seleção e organização dos saberes escolares, pois os colégios ensinavam o latim, enquanto as escolas elementares de caridade transmitiam, sobretudo, a língua vernácula. A perspectiva de análise histórica de Petitat, portanto, é claramente de corte sociológico.

De outra parte, os trabalhos dos cientistas sociais de língua espanhola apresentam uma leitura fundamentada na perspectiva foucaultiana, mas com matizes diferentes. Varela e Alvarez-Uría (1991) marcam, de forma mais clara, a ruptura dos processos educativos com as Reformas Religiosas, de modo que o fanatismo é considerado uma das alavancas da modernidade. Argumentam que as disputas religiosas transformaram o território europeu numa área de missão permanente e no palco das cruéis guerras de religião. As práticas educativas que emergiram na Idade Moderna são vistas como estratégias da cruzada moderna, que transformaram o currículo escolar numa trincheira. Pelo fato de seu referencial espacial ser a Espanha, os autores focalizam com mais propriedade a presença jesuítica e dão exemplos instigantes da corte espanhola. Varela e Alvarez-Uría (1991) marcam mais claramente a existência de três modos de educação na Idade Moderna e acentuam a diferenciação social e escolar de classe e de gênero. Em todos os projetos educativos da primeira modernidade, chamam a atenção para a exclusão das mulheres.

De forma menos sociológica e mais genealógica, Dussel e Caruso (2003) constatam diferenças de classes sociais entre os colégios e as escolas elementares, bem como, fundamentados em Elias (1989), sinalizam en passant que os humanistas como Erasmo de Roterdão produziram livros para educar os filhos da nobreza da corte. Assim, sublinham a apropriação da disciplina escolar presente na Ratio Studiorum por La Salle, tanto na sua experiência educativa como no seu manual pedagógico para as escolas elementares. Ademais, de forma singular, os historiadores argentinos embutem na confessionalização social na Idade Moderna a produção de A Didactica Magna de Comênio, um discurso pedagógico em defesa do método global que estava em circulação e em (re)construção. Enfim, a obra dos historiadores argentinos é mais transversalizada pela perspectiva histórica foucaultiana, que constata o nascimento da disciplina sem entranhá-la explicitamente por marcadores sociais. 


\section{REFERÊNCIAS}

ARIÈS, Philippe. História social da família e da criança, 2. ed. Rio de Janeiro: Guanabara, 1981.

CARVALHO, M. M. C.; HANSEN, J. A. Modelos culturais e representação: uma leitura de Roger Chartier. Varia História, Belo Horizonte, n. 16, p. 7-24, set. 1996.

CHARTIER, Roger. À beira da falésia: a história entre certezas e inquietudes. Porto Alegre: Ed. Universidade/UFRGS, 2002.

CHARTIER, R. Entre poder y placer: cultura escrita y literatura en la Edad Moderna.

Madrid: Cátedra, 2000.

DALLABRIDA, Norberto. Moldar a alma plástica da juventude. Educação Unisinos Revista do Programa de Pós-Graduação em Educação da Universidade do Vale do Rio dos Sinos, São Leopoldo, v. 5, n. 8, p. 133-50, jan.jun. 2001.

DURKHEIM, Émile. A evolução pedagógica. Porto Alegre: Artes Médicas, 1995.

DUSSEL, Inés; CARUSO, Marcelo. A invenção da sala de aula: uma genealogia das formas de ensinar. São Paulo: Moderna, 2003 (Educação Em pauta).

ELIAS, Norbert. El proceso de la civilización: investigaciones sociogenéticas y psicogenéticas. Madrid: Fondo de Cultura Economica, 1989.

ELIAS, Norbert. La sociedad cortesana. Madrid: Fondo de Cultura Económica, 1993.

FIÉVET, Michel. Les enfants pauvres à l'école: la révolution scolaire de Jean-Baptiste de La Salle. Paris: Editions Imago, 2001.

FOUCAULT, Michel. Vigiar e punir: nascimento da prisão, 10. ed. Petrópolis, RJ: Vozes, 1993.

PETITAT, André. Produção da escola/produção da sociedade: análise sócio-histórica de alguns momentos decisivos da evolução escolar no ocidente. Porto Alegre: Artes Médicas, 1994.

ROUSSEAU, Jean-Jacques. Emílio ou a educação. São Paulo: Difel, 1968 (Clássicos Garnier).

RUIZ, Enrique Martínez (Ed.). Diccionario de historia moderna de España. Madrid: Ediciones ISTMO, 1998 (Fundamentos, 136).

VARELA, Julia. Modos de educación en la España de la contrarreforma. Madrid: La Piqueta, 1983 (Genealogía del poder, 9).

VARELA, Julia, ALVAREZ-URÍA, Fernando. Arqueología de la escuela. Madrid: La Piqueta, 1991 (Genealogía del poder, 20). 
WEBER, Max. A Ética protestante e o espírito do capitalismo, 3. ed. São Paulo: Livraria Pioneira Editora, 1983 (Biblioteca Pioneira de Ciências Sociais).

\section{Dados dos AUtores:}

\section{Norberto Dallabrida}

Possui graduação em História pela Universidade Federal de Santa Catarina (1988), graduação em Pedagogia pela Universidade do Estado de Santa Catarina (1984), mestrado em História pela Universidade Federal de Santa Catarina (1993) e doutorado em História Social pela Universidade de São Paulo (2001). Universidade do Estado de Santa Catarina - UDESC. Florianópolis/SC - Brasil. norbertodallabrida@gmail.com 